\title{
Métodos de manejo de aveia preta para evitar sua ressurgência como planta daninha em trigo
}

\author{
Black oat management methods to avoid its resurgence as weed plant in wheat
}

\author{
Renato Serena Fontaneli I Antonio FaganelloII Arcênio Sattler ${ }^{\text {II }}$ Leandro Vargas II
}

\section{RESUMO}

A aveia preta é a cultura de cobertura de inverno importante no sul do Brasil. Entretanto, a aveia preta, do mesmo modo que o azevém anual, é uma planta daninha em culturas comerciais de inverno. Dois experimentos em blocos casualizados foram conduzidos na Embrapa Trigo, em Passo Fundo, Rio Grande do Sul (RS), para estudar métodos de manejo de aveia preta em dois estádios de desenvolvimento, antese e grão leitoso, que evitem a transformação dessa espécie em planta daninha, em trigo cultivado em sucessão com soja. As parcelas tiveram área útil de $60 \mathrm{~m}^{2}$. Nove métodos de manejo foram estudados: dessecação; rolagem e dessecação; fenação; ensilagem; roçada; trituração; rolagem, mediante uma operação com rolo faca; gradagem; colheita mecânica de grãos. A biomassa média acumulada na antese foi de $5.016 \mathrm{~kg}$

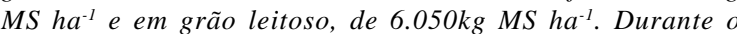
verão, a soja não foi afetada pelos métodos de manejo de aveia e teve produtividade média de $2.080 \mathrm{~kg} \mathrm{ha}^{-1}$. Na safra de inverno do ano seguinte, os métodos de manejo aplicados na antese tiveram produtividade média de grãos de trigo de $2.472 \mathrm{~kg} \mathrm{ha}^{-1}$, e a densidade de espigas foi de 355 espigas $\mathrm{m}^{-2}$, nas parcelas que foram dessecadas antes da semeadura da cultura de trigo, e $836 \mathrm{~kg} \mathrm{ha}^{-1}$ e 225 espigas $\mathrm{m}^{-2}$, nas parcelas sem dessecação. Nos manejos aplicados no estádio de grão leitoso, a produtividade média foi de $1.733 \mathrm{~kg} \mathrm{ha}^{-1}$, com densidade de espigas de 334 espigas $\mathrm{m}^{-2}$. Nas parcelas sem dessecação, a cultura de trigo foi totalmente dominada pelas plantas espontâneas de aveia, resultantes dos métodos de manejo aplicados no inverno anterior. Métodos de manejo da aveia exclusivamente mecânicos, em qualquer estádio de desenvolvimento da cultura, pode transformar essa espécie em planta daninha, nos cultivos de inverno subsequentes. Esse problema é evitado com dessecação até a antese, pois, depois desse estádio, nenhum método de manejo testado foi capaz de evitar a maturação fisiológica de sementes de aveia, tornando essa espécie uma planta daninha potencial para as safras de inverno subsequentes e obrigando a dessecação das plantas emergidas antes da semeadura de culturas comerciais.
Palavras-chave: Avena strigosa, planta daninha, manejo mecânico, rolagem, gradagem.

\section{ABSTRACT}

Black oat is an important winter cover crop in south Brazilian. However, it is a weed problem in cool season grain crops as well as ryegrass. Two trials in a randomized complete block design were conducted at Embrapa Trigo in Passo Fundo, Rio Grande do Sul state. This research aimed to study different oat management methods applied on black oat at anthesis and milk stage to avoid it becoming a weed plant in wheat cropped after soybean. The plot area was $60 \mathrm{~m}^{2}$. Nine treatments were tested, in both trials: spray herbicide; roll plus herbicide; hay harvest; silage harvest; mowing; grinding, silage; rolling; disking; and grain harvesting. The average total biomass at anthesis was 5,016kg DM ha-1 and at milk stage was

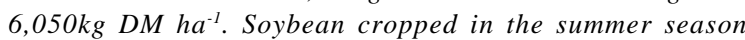
yield 2,080 $\mathrm{kg} \mathrm{ha}^{-1}$ and it was not affected by black oat treatments. During the second year, the wheat plots sprayed herbicide before planting yielded $2,472 \mathrm{~kg} \mathrm{ha}^{-1}$ and spike density of $355 \mathrm{~m}^{-2}$, however plots without herbicide yielded $836 \mathrm{~kg} \mathrm{ha}^{-1}$ and had 225 spikes $\mathrm{m}^{-2}$. On black oat milk stage managements the yield average was $1,733 \mathrm{~kg} \mathrm{ha}^{-1}$ and 334 spikes $\mathrm{m}^{-2}$, on sprayed herbicide plots before planting. In opposite, the plots without herbicide, wheat plants were completely dominated by resurgent black oat plants, due to managements applied during previous winter. Mechanical management methods applied only in black oat development stages allowed seeds germination during winter crops cycle. This problem is avoided spraying herbicide before oat anthesis, because after that any management method tested was unsuccessful to control oat after the following winter crops, so is necessary to spray herbicide before seeding winter cash crops.

Key words: Avena strigosa, weed plant, mechanical management, rolling, disking.

IEmbrapa Trigo, Universidade de Passo Fundo (UPF), CP 451, 99001-970, Passo Fundo, RS, Brasil. E-mail: renatof@cnpt.embrapa.br.

*Autor para correspondência.

"Embrapa Trigo, Passo Fundo, RS, Brasil. 


\section{INTRODUÇÃO}

A minimização do processo de degradação de solos, ocorrente nas regiões produtoras de cereais de inverno no sul do Brasil, requer ações integradas de manejo conservacionista de solo. $\mathrm{O}$ primeiro passo consiste na redução de perdas de solo, de água e de nutrientes por erosão. Nesse sentido, o plantio direto tem se mostrado como o mais eficaz sistema conservacionista de manejo de solo, apresentando percentuais de redução de perdas de solo por erosão superiores a $90 \%$, quando comparado ao preparo convencional. Para que esse sistema seja viabilizado e possa expressar toda sua potencialidade, a cobertura vegetal do solo deve ser duradoura (FURLANETTO et al., 2006), bem como apresentar alta relação $\mathrm{C} / \mathrm{N}$.

A aveia preta (Avena strigosa Schreb.), por suas características de compatibilidade de ciclo com as demais espécies do sistema produtivo regional, de elevada produção de fitomassa, de abundante sistema radical, de rusticidade (CALEGARI et al., 1992), diante de problemas fitossanitários e de baixa fertilidade química do solo (MURPHY \& HOFFMAN, 1992), de adaptabilidade a cortes mecânicos e ao pastoreio (AGUINAGA et al., 2006; FONTANELI \& SANTOS, 1999). Além disso, é conservada na forma de feno e silagem, pelo elevado valor nutritivo. Pela facilidade de produção e processamento de sementes, passou a integrar os sistemas de produção sul-brasileiros de forma intensiva, sendo usada como cultura de cobertura de solo (SALTON et al., 1998) e como componente principal em pastagens anuais de inverno isoladamente ou em consorciações (FONTANELI \& FREIRE Jr., 1991). Apesar dos inúmeros benefícios que a aveia preta pode propiciar ao processo produtivo, cuidados com o seu manejo são indispensáveis para evitar que essa espécie se transforme em planta daninha (FONTANELI et al., 1997). Muitos métodos de manejo são utilizados com a aveia preta. Dentre eles, os destinados à produção de forragem para os animais em pastejo direto ou armazenados na forma de feno, silagem ou grãos. Quando usada para cobertura de solo ou colheita de grãos, em função de parte das sementes apresentarem dormência, a aveia preta tornando-se planta daninha no cultivo de cereais de inverno, no ano subsequente. Muitos agricultores usam métodos mecânicos (rolo faca, gradagem e até trilhos), sem observar o estádio de desenvolvimento. A aveia preta ressurgente rivaliza com o azevém anual como planta daninha em culturas comerciais, tais como o trigo, a aveia branca, a cevada, o triticale e o centeio. Embora existam herbicidas específicos, de certa maneira eficientes, eles aumentam o custo de produção de culturas que normalmente têm baixa rentabilidade. A aveia preta, como planta daninha na cultura de trigo, tem se mostrado redutora de produtividade e de qualidade de produto, principalmente na fabricação de farinha para fins de panificação. Tendo por justificativa essa situaçãoproblema, este trabalho teve por objetivo estudar métodos de manejo de aveia preta que evitem a transformação dessa espécie em planta daninha para as culturas comerciais, produtoras de grãos, cultivadas na safra de inverno posterior.

\section{MATERIAL E MÉTODOS}

Dois experimentos de manejo de aveia preta foram conduzidos na área experimental do Centro Nacional de Pesquisa de Trigo, Embrapa Trigo, em Passo Fundo, Rio Grande do Sul (RS), localizado na longitude $28^{\circ} 15^{\prime} \mathrm{S}$, latitude de $52^{\circ} 24^{\prime}$ W W altitude de 684m. O ensaio transcorreu no período de abril de 1993 a novembro de 1994, em Latossolo Vermelho Distrófico típico (EMBRAPA, 1999), de textura argilosa e relevo suavemente ondulado. O primeiro ensaio buscou estudar técnicas de manejo no estádio de antese, e o segundo, no estádio de grão leitoso, ambos sendo conduzidos até a colheita de trigo cultivado na safra seguinte em resteva de soja. Os teores médios de argila, silte e areia, na camada de $0-20 \mathrm{~cm}$ de profundidade, são, respectivamente, de $490 \mathrm{~g} \mathrm{~kg}^{-1}, 200 \mathrm{~g} \mathrm{~kg}^{-1}$ e $310 \mathrm{~g} \mathrm{~kg}^{-1}$. As características químicas do solo determinadas antes do cultivo da aveia indicavam $\mathrm{pH}$ em água de 5,6; índice SMP de 5,8, 35 $\mathrm{mg} \mathrm{kg}^{-1}$ de P extraível; 220 $\mathrm{mg} \mathrm{kg}^{-1}$ de $\mathrm{K}$ trocável; 3,3\% de $\mathrm{MO} ; 1,6 \mathrm{mmol}_{\mathrm{c}} \mathrm{dm}^{-3}$ de $\mathrm{Al}$ trocável; 55,4mmol dm ${ }^{-3}$ de Ca trocável e 23,7 $\mathrm{mmol}_{\text {c }}$ $\mathrm{dm}^{-3}$ de Mg trocável. O sistema de produção incluiu, nos últimos quatro anos, o monocultivo da soja no verão, em sucessão ao trigo no inverno ou pousio.

O delineamento experimental foi em blocos casualizados, com quatro repetições e nove tratamentos. As unidades experimentais apresentavam área útil de $60 \mathrm{~m}^{2}$, com 5,0m de lado e 12,0m de comprimento. Os tratamentos aplicados no manejo de aveia preta, antes da semeadura da soja, nos dois experimentos, foram: dessecação, mediante o uso de herbicida glyphosate, na dose de $1,5 \mathrm{~L} \mathrm{ha}^{-1}$ de produto comercial; rolagem, mediante uma operação com rolo faca, seguida de dessecação complementar com o uso de glyphosate, na dose de $1,5 \mathrm{~L}$ ha $^{-1}$ de produto comercial; fenação, mediante corte com segadora de barra, secagem da forragem sobre a unidade experimental e posterior remoção manual do feno; ensilagem, mediante o emprego de ensiladora; roçada, mediante uma operação com roçadora de navalha giratória; trituração, mediante uma operação com triturador de palha; rolagem, mediante uma operação com rolo faca; gradagem, 
mediante uma operação com grade niveladora de discos semiaberta; colheita de grãos, mediante o emprego de um colhedora de parcelas experimentais.

A aveia preta cultivar 'Comum' foi estabelecida sob plantio direto na resteva de soja, no dia 18 de maio de 1993, empregando 350 sementes aptas $\mathrm{m}^{-2}$ e sem adubação. Nenhum trato cultural complementar foi praticado na cultura, exceto os métodos de manejo planejados.

No manejo da aveia preta, no estádio de antese, todos os métodos de manejo, exceto o de colheita de grãos, foram aplicados no período de 16 a 18 de outubro de 1993. No manejo da aveia preta, no estádio de grão leitoso, esses mesmos métodos de manejo foram aplicados no dia 29 de outubro. O método de manejo colheita de grãos foi aplicado em ambos os ensaios, no dia 22 de novembro de 1993.

A semeadura da cultura da soja, cultivar 'BR 16', em sequência aos manejos de aveia preta, foi realizada em 10 de novembro, nas unidades experimentais de todos os métodos de manejo estudados, exceto no método de colheita de grãos, que foi semeado em 22 de novembro. Os tratos culturais praticados nessa espécie resumiram-se ao controle de plantas daninhas, mediante o uso de herbicidas pósemergentes (Bentazon - Basagran ${ }^{\circledR}$ ), e ao combate à lagarta da soja, mediante o uso de inseticida específico.

Em junho de 1994, na época de semeadura da cultura de trigo, em sequência à cultura de soja, no ensaio de manejo de aveia preta no estádio de antese, foi observada a presença generalizada de aveia preta, fruto da ressemeadura natural, em todos os métodos de manejo do ensaio de manejo da aveia preta no estádio de grão leitoso, exceto nos métodos de manejo dessecação e rolagem seguida de dessecação complementar., Para a semeadura da cultura de trigo, cada unidade experimental foi dividida ao meio, no sentido longitudinal, sendo metade dessecada, mediante o uso de glyphosate, na dose de $1,5 \mathrm{~L} \mathrm{ha}^{-1} \mathrm{de}$ produto comercial, e metade permanecendo sem dessecação. Dessa forma, os ensaios passaram a ter, durante o ciclo da cultura de trigo, faixas, com e sem dessecação da aveia preta germinada espontaneamente no outono de 1994.

A semeadura da cultura de trigo, cultivar 'Embrapa 16', foi realizada em 21 de junho de 1994, empregando-se 320 sementes aptas $\mathrm{m}^{-2}$ e $250 \mathrm{~kg} \mathrm{ha}^{-1} \mathrm{de}$ adubo da fórmula 5-25-25 ( $\left.\mathrm{N}-\mathrm{P}_{2} \mathrm{O}_{5}-\mathrm{K}_{2} \mathrm{O}\right)$, acrescida de $45 \mathrm{~kg} \mathrm{ha}^{-1}$ de nitrogênio em cobertura (uréia), 30 dias após a emergência das plantas. Nenhum outro trato cultural foi requerido durante o ciclo dessa cultura.

Os dados experimentais foram submetidos à análise de variância, e as médias foram comparadas pelo teste de Duncan a 5\%.

\section{RESULTADOS E DISCUSSÃO}

Na tabela 1, estão sumariados os registros de precipitação pluvial e temperaturas médias ocorrentes em Passo Fundo, por ocasião da realização do experimento. Observou-se que os meses de abril de 1993, agosto, setembro e dezembro de ambos os anos tiveram precipitação abaixo do normal. Já em agosto de 1993 e 1994 foi registrada precipitação normal de 9\% e 27\%, respectivamente. Entretanto, houve precipitação maior em julho, novembro e dezembro de 1993 e em fevereiro, abril, junho e julho de 1994, atingido mais do que o dobro em alguns meses. No que diz respeito a temperaturas médias, foram registrados aumentos de cerca de $1,5^{\circ} \mathrm{C}$ em abril e outubro de 1993 e de $1,1^{\circ} \mathrm{C}$ a $2,2^{\circ} \mathrm{C}$ em maio, setembro, outubro e dezembro de 2004 . Temperatura abaixo da normal ocorreu apenas no mês de julho de 1993.

A aveia preta, cultivada no inverno de 1993, embora não tenha sido adubada, prática essa normal no cultivo de espécies destinadas à cobertura de solo, atingiu desenvolvimento vegetativo adequado. No estádio de antese, a estatura média das plantas foi de 1,05m, e a biomassa aérea acumulada foi de 5,02t MS ha $^{-1}$, amostrada 7,0cm acima da superfície do solo. No estádio de grão leitoso, esses mesmos parâmetros foram, respectivamente, de 1,31m e 6,05t $\mathrm{MS} \mathrm{ha}^{-1}$ de biomassa, dados de acordo com os encontrados na literatura (FLOSS, 1988). Tanto no manejo da aveia preta no estádio de antese, como no estádio de grão leitoso, o perfilhamento médio dessa cultura atingiu 3,3 afilhos por planta, e a produtividade média de grãos, avaliada no método de manejo de colheita de grãos, foi de $700 \mathrm{~kg}$ $\mathrm{ha}^{-1}$.

A cultura da soja, em ambos os ensaios, auferiu um rendimento médio de $2.080 \mathrm{~kg} \mathrm{ha}^{-1}$, não apresentando diferenças significativas $(\mathrm{P}>0,05)$ entre os métodos de manejo aplicados na cultura de aveia preta. A cultura de trigo, cultivada na safra de inverno de 1994, teve a produtividade de grãos e a densidade de espigas sensivelmente afetadas pelos métodos de manejo aplicados na cultura de aveia preta durante o inverno de 1993 (Tabelas 2 e 3). No ensaio manejo da aveia preta, no estádio de antese, a produtividade média de grãos e a densidade de espigas variaram de $2.472 \mathrm{~kg}$ ha $^{-1}$ e 355 espigas $\mathrm{m}^{-2}$, nas unidades experimentais que foram dessecadas antes da semeadura da cultura de trigo, a 836 kg ha-1 e 225 espigas $\mathrm{m}^{-2}$, nas unidades experimentais sem dessecação antes da semeadura do trigo. No ensaio manejo de aveia, no estádio de grão leitoso, essas variações foram mais drásticas, visto que, nas unidades experimentais com dessecação antes da semeadura da cultura de trigo, a produtividade média 
Tabela 1 - Precipitação pluviométrica e temperatura média normais e registradas na Embrapa Trigo, nos anos de 1993 e 1994, em Passo Fundo, RS.

\begin{tabular}{|c|c|c|c|c|c|c|c|}
\hline \multicolumn{4}{|c|}{ 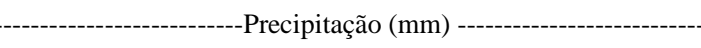 } & \multicolumn{4}{|c|}{ 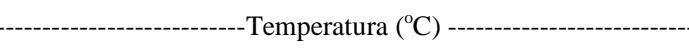 } \\
\hline Mês & 1993 & 1994 & Normal & Mês & 1993 & 1994 & Normal \\
\hline Janeiro & 255,5 & 55,2 & 143,4 & Janeiro & 22,6 & 21,9 & 22,1 \\
\hline Fevereiro & 152,7 & 333,6 & 148,3 & Fevereiro & 20,2 & 21,2 & 21,9 \\
\hline Março & 197,7 & 69,8 & 121,3 & Março & 20,2 & 19,5 & 20,6 \\
\hline Abril & 75,0 & 193,6 & 118,2 & Abril & 19,0 & 17,7 & 17,6 \\
\hline Maio & 176,2 & 152,2 & 131,3 & Maio & 14,7 & 16,7 & 14,3 \\
\hline Junho & 137,2 & 198,8 & 129,4 & Junho & 12,6 & 12,4 & 12,7 \\
\hline Julho & 284,0 & 243,0 & 153,4 & Julho & 11,6 & 13,5 & 12,8 \\
\hline Agosto & 15,2 & 46,0 & 165,7 & Agosto & 14,1 & 14,6 & 14,0 \\
\hline Setembro & 136,5 & 161,7 & 206,8 & Setembro & 14,3 & 16,5 & 14,8 \\
\hline Outubro & 154,2 & 308,7 & 167,1 & Outubro & 19,3 & 18,8 & 17,7 \\
\hline Novembro & 273,9 & 138,1 & 141,4 & Novembro & 19,9 & 19,2 & 19,8 \\
\hline Dezembro & 259,0 & 235,2 & 161,5 & Dezembro & 21,8 & 23,5 & 21,5 \\
\hline
\end{tabular}

Fonte: Embrapa Trigo.

foi de $1.733 \mathrm{~kg} \mathrm{ha}^{-1}$, com densidade de 334 espigas $\mathrm{m}^{-2}$. Já nas unidades experimentais sem dessecação, a cultura de trigo foi totalmente dominada pelas plantas de aveia preta, germinadas espontaneamente, resultantes dos diferentes métodos de manejo aplicados no inverno anterior.

No manejo da aveia preta, no estádio de antese, sem dessecação nas unidades experimentais antes da semeadura da cultura de trigo, os métodos de manejo dessecação, em 1993, e rolagem seguida de dessecação complementar, em 1993, se destacaram em relação aos demais, propiciando as produtividades mais elevadas de grãos de trigo (Tabela 2). Esses dois métodos de manejo de aveia preta foram os únicos que viabilizaram a produção de grãos de trigo, sem o auxílio de dessecação das unidades experimentais antes da semeadura dessa cultura na safra de inverno subsequente à do cultivo de aveia preta. $\mathrm{O}$ sucesso desses dois métodos de manejo residiu na ação da dessecação no estádio de antese, a qual interrompeu o

Tabela 2 - Rendimento de grãos de trigo em função de diferentes métodos de manejo de aveia preta nos estádios de antese e de grão leitoso, na safra de inverno de 1993, e do uso de dessecante ou não antes da semeadura da cultura de trigo na safra de inverno de 1994.

\begin{tabular}{|c|c|c|c|c|}
\hline \multirow{3}{*}{ Métodos de manejo } & \multicolumn{4}{|c|}{-----------------Estádio de antese------------------ } \\
\hline & \multirow[b]{2}{*}{ com } & \multirow{2}{*}{$\begin{array}{r}\text {-Desse } \\
\text { sem }\end{array}$} & \multirow[b]{2}{*}{ com } & \multirow[b]{2}{*}{ sem } \\
\hline & & & & \\
\hline & \multicolumn{4}{|c|}{ - } \\
\hline Dessecação & 2.944 а & 1.740 & $1.971 \mathrm{~ns}$ & $*$ \\
\hline Rolagem + Dessecação & $2.825 \mathrm{ab}$ & 1.443 & 1.814 & $*$ \\
\hline Fenação & $2.658 \mathrm{abc}$ & 176 & 1.753 & * \\
\hline Ensilagem & $2.560 \mathrm{abc}$ & 473 & 1.690 & $*$ \\
\hline Roçada & $2.523 \mathrm{abc}$ & 401 & 1.800 & * \\
\hline Trituração & $2.376 \mathrm{abc}$ & 780 & 1.762 & * \\
\hline Rolagem & 2.203 bc & $*$ & 1.615 & * \\
\hline Gradagem & $2.163 \mathrm{bc}$ & $*$ & 1.684 & $*$ \\
\hline Colheita de grãos & 1.993 с & 216 & 1.504 & $*$ \\
\hline Média & 2.472 & 581 & 1.733 & $*$ \\
\hline CV ( \%) & 11,98 & - & 14,01 & \\
\hline
\end{tabular}

Médias seguidas de mesma letra, na coluna, não diferem significativamente pelo teste de Tukey (P>0,05). ns = não significativo.

* A cultura de trigo foi dominada pela aveia preta germinada espontaneamente, que atuou como planta daninha que comprometeu a colheita.

Ciência Rural, v.39, n.7, out, 2009. 
Tabela 3 - Densidade de espigas de trigo em função de diferentes métodos de manejo de aveia preta nos estádios de antese e de grão leitoso, na safra de inverno de 1993, e do uso de dessecante ou não antes da semeadura da cultura de trigo na safra de inverno de 1994.

\begin{tabular}{|c|c|c|c|c|}
\hline \multirow[t]{2}{*}{ Métodos de manejo } & \multirow[b]{2}{*}{ com } & \multirow[b]{2}{*}{ sem } & \multirow[b]{2}{*}{ com } & \multirow[b]{2}{*}{ sem } \\
\hline & & & & \\
\hline & \multicolumn{4}{|c|}{--------------------------------------------------------espigas m ${ }^{-2}--$} \\
\hline Dessecação & $364 n s$ & 300 & 332ns & $*$ \\
\hline Rolagem + Dessecação & 375 & 275 & 340 & $*$ \\
\hline Fenação & 351 & 133 & 318 & $*$ \\
\hline Ensilagem & 328 & 238 & 305 & $*$ \\
\hline Roçada & 362 & 146 & 350 & $*$ \\
\hline Trituração & 342 & 259 & 320 & $*$ \\
\hline Rolagem & 358 & $*$ & 342 & $*$ \\
\hline Gradagem & 376 & $*$ & 359 & $*$ \\
\hline Colheita de grãos & 335 & $*$ & 335 & $*$ \\
\hline Média & 355 & 225 & 334 & $*$ \\
\hline CV (\%) & 11,43 & & 9,43 & \\
\hline
\end{tabular}

* A cultura de trigo foi dominada pela aveia preta germinada espontaneamente, que atuou como planta daninha que comprometeu a colheita (inferior a 100 plantas $\mathrm{m}^{-2}$ ).

ns = não significativo.

ciclo reprodutivo da aveia preta, evitando a formação e/ou a maturação fisiológica de sementes dessa espécie.

Essa conclusão torna-se evidente ao compararem-se os métodos de manejo rolagem e dessecação complementar e somente rolagem, em que percebe-se que a rolagem isoladamente não teve o mesmo comportamento da rolagem seguida de dessecação, principalmente quando não foi realizada a dessecação antes da semeadura da cultura de trigo. A cultura de trigo, no método de manejo rolagem, foi totalmente dominada pelas plantas de aveia preta germinadas espontaneamente, cujo trigo com a densidade de somente 45 espigas $\mathrm{m}^{-2}$, resultou em perda total, ou seja em produtividade nula de grãos (Tabela 2). Nesse método de manejo, rolagem, como nos demais métodos de manejo, com exceção da dessecação e da rolagem seguida pela dessecação em 1993, ocorreu rebrote de plantas de aveia preta, com posterior ciclo de vida completo, e/ou não houve interrupção completa do ciclo reprodutivo da aveia preta, levando-se à formação de sementes fisiologicamente maduras, o que, consequentemente, potencializou essa espécie como planta daninha para a safra de inverno subsequente, que permitiu colheita de apenas 176 a $780 \mathrm{~kg} \mathrm{ha}^{-1}$ de trigo (Tabela 2).

O manejo da aveia preta, no estádio de antese (extrusão das anteras), com dessecação nas unidades experimentais antes da semeadura da cultura de trigo, permitiu colheita de grãos de 1.993 a $2.944 \mathrm{~kg} \mathrm{ha}^{-1}$ (Tabela
2). Nesse manejo, praticamente houve ausência de panículas de aveia preta na colheita de trigo, atingindo um máximo de 1,2 panículas $\mathrm{m}^{-2}$, por ocasião da colheita de trigo em 1994. Os melhores métodos de manejo foram dessecação, rolo faca seguido de dessecação complementar antes da semeadura da soja, fenação, ensilagem e roçada. Entretanto, somente os dois primeiros, que incluíram dessecação, superaram os métodos de manejo rolagem, gradagem e colheita de grãos.

No manejo da aveia preta, no estádio de grão leitoso, a cultura de trigo só auferiu rendimento de grãos nas unidades experimentais que foram dessecadas antes da semeadura (Tabela 2). A produtividade média de grãos foi de $1.733 \mathrm{~kg} \mathrm{ha}^{-1}$, não havendo diferenças significativas $(\mathrm{P}>0,05)$ entre os métodos de manejo de aveia preta praticados na safra de inverno de 1993. Nos métodos de manejo sem dessecação antes da semeadura da cultura de trigo, as plantas de aveia preta produziram sementes viáveis, formando um banco de sementes, característica exibida em plantas silvestres (MARCOS FILHO, 2005). Grande número dessas sementes permaneceu dormente no solo e sobreviveu à ação de agentes bióticos e abióticos da primavera ao outono. Essas sementes, quando obtiveram ambiente favorável, fim de verão/outono, germinaram e dominaram as unidades experimentais, resultando em produtividades de trigo nulas. Esses resultados demonstram que, independentemente do método de 
manejo aplicado na aveia preta, no estádio de grão leitoso, essa espécie pode tornar-se uma planta daninha potencial para a safra de inverno subsequente, pois nessa fase do ciclo reprodutivo nenhum método de manejo testado foi capaz de impedir a formação de sementes fisiologicamente maduras e/ou o rebrote de plantas, com posterior ciclo de vida completo.

\section{CONCLUSÕES}

O emprego de aveia preta, como cultura de cobertura de solo no sistema plantio direto, manejada por meio de métodos exclusivamente mecânicos (fenação, ensilagem, roçada, trituração, rolagem e gradagem), em qualquer estádio de desenvolvimento da cultura, bem como a colheita de grãos, são ineficientes, pois podem transformar essa espécie em planta daninha nos cultivos de inverno subsequentes. Essa situação-problema foi evitada quando o manejo químico, por meio de dessecação, foi aplicado no estádio de antese. A partir desse estádio de desenvolvimento, nenhum método de manejo testado foi capaz de evitar a maturação fisiológica de sementes de aveia preta, tornando essa espécie uma planta daninha potencial para as safras de inverno subsequentes e obrigando a dessecação das plantas emergidas espontaneamente, antes da semeadura de culturas comerciais destinadas à produção de grãos.

\section{REFERÊNCIAS}

AGUINAGA, A.A.Q. et al. Produção de novilhos superprecoces em pastagem de aveia e azevém submetidas a diferentes alturas de manejo. R Bras Zootec, v.35, n.4, p.1765-1773, 2006 (supl.). Disponível em : <http://www.scielo.br/scielo.php?script=sci_arttext\&pid=S151635982006000600026\&lng=pt\&nrm=iso\&tlng=pt $>$. Acesso em: 27 abr. 2009. doi: 10.1590/S1516-35982006000600026.
CALEGARI, A. et al. Adubação verde no sul do Brasil. Rio de Janeiro: AS-PTA, 1992. 346p.

EMBRAPA. Centro Nacional de Pesquisa de Solos (Rio de Janeiro, RJ). Sistema brasileiro de classificação de solos. Brasília: Embrapa Produção da Informação; Rio de Janeiro: Embrapa Solos, 1999. 412p.

FLOSS, E.L. Aveia. In: BAIER, A.C. et al.. As lavoura de inverno. Rio de Janeiro: Globo, 1988. p.15-74.

FONTANELI, R.S. et al. Manejo de aveia preta como cobertura de solo no sistema plantio direto. Passo Fundo: Embrapa Trigo/Projeto METAS, 1997. 18p. (Projeto METAS. Boletim Técnico, 2).

FONTANELI, R.S.; FREIRE JUNIOR, N. Avaliação de consorciações de aveia e azevém - anual com leguminosas de estação fria. Pesq Agropec bras, p.26, n.5, p.623-630, 1991.

FONTANELI, R.S.; SANTOS, H.P. dos. Efeito de pastagens de aveia preta e de aveia preta + ervilhaca sobre o ganho de peso animal. Passo Fundo: Embrapa Trigo, 1999. (Comunicado Técnico 3).

FURLANETTO, D. et al. Evolução da cobertura do solo e persistência da fitomassa de diferentes genótipos de aveia (Avena strigosa Schreb. e Avena sativa L.) sobre o solo. In: FONTOURA, S. (Org.) REUNIÃO DA COMISSÃO BRASILEIRA DE PESQUISA DE AVEIA. Resultados experimentais. Guarapuava: Fundação Agrária de Pesquisa Agropecuária, 2006. p.98-101.

MARCOS FILHO, J. Fisiologia de sementes de plantas cultivadas. Piracicaba: Fealq, 2005. 495p.

MURPHY, J.P; HOFFMAN, L.A. The origin, history, and production of Oat. In: MARSHALL, H.G.; SORRELLS, M.E. (co-eds.). Oat science and technology. Madison, WI: ASACSSA, 1992. Chap.1. p.1-28

SALTON, J.C. et al. Sistema plantio direto. O produtor pergunta a EMBRAPA responde. Brasília: Embrapa, 1998. p.40-45. 